\title{
Clinicopathological and Prognostic Significance of Circulating Tumor Cells in Patients with Head and Neck Cancer: A Meta-Analysis
}

\author{
Ruiwan Chen', Yu Zhou' ${ }^{2}$, Bixiu Wen ${ }^{*}$ \\ ${ }^{1}$ Department of Radiotherapy, The First Affiliated Hospital, Sun Yat-sen University, Guangzhou, China \\ ${ }^{2}$ Department of General Surgery, Guangdong General Hospital, Guangzhou, China \\ Email: *wenbix@mail.sysu.edu.cn
}

Received 26 December 2015; accepted 20 May 2016; published 23 May 2016

Copyright (C) 2016 by authors and Scientific Research Publishing Inc.

This work is licensed under the Creative Commons Attribution International License (CC BY).

http://creativecommons.org/licenses/by/4.0/

(c) () Op Och Access

\begin{abstract}
Purpose: The aim of the study was to evaluate the association between clinicopathological and prognostic significance and circulating tumor cells (CTCs) in patients with head and neck cancer. Methods: We searched PubMed, MEDLINE, BioMed, and EMbase databases for studies that assessed the association between clinicopathological and prognostic significance and CTCs in patients with head and neck cancer. Studies obtained from search strategy were screened using pre-specified criteria, and necessary data were retrieved for meta-analysis. Results: Seventeen studies with 816 patients were eligible for combined analysis. Presence of CTCs in peripheral blood was significantly associated with $\mathrm{N}$ stage $(\mathrm{OR} 0.50,95 \% \mathrm{CI}[0.30,0.81], \mathrm{n}=10, \mathrm{P}=0.005)$. Patients in the high-CTC group were significantly associated with poorer disease-free survival (DFS; $\mathrm{HR}=1.73,95 \% \mathrm{CI}[1.01-2.96], \mathrm{P}=0.050)$ and poorer overall survival $(\mathrm{OS} ; \mathrm{HR}=\mathbf{2 . 5 3}, 95 \% \mathrm{CI}[1.37$ 4.69] $P=0.003$ ). Further analyses indicated strong prognostic powers of CTCs in non-RT-PCR group and pre-treatment group. Conclusion: Our meta-analysis indicates that presence of CTCs is associated with higher $\mathrm{N}$ stage and poorer prognosis in patients with head and neck cancer. The potential for further clinical application may be needed for further investigation.
\end{abstract}

\section{Keywords}

Circulating Tumor Cells, Head and Neck Cancer, Clinicopathological Characteristic, Prognosis, Meta-Analysis

${ }^{*}$ Corresponding author.

How to cite this paper: Chen, R.W., Zhou, Y. and Wen, B.X. (2016) Clinicopathological and Prognostic Significance of Circulating Tumor Cells in Patients with Head and Neck Cancer: A Meta-Analysis. International Journal of Medical Physics, Clinical Engineering and Radiation Oncology, 5, 138-149. http://dx.doi.org/10.4236/ijmpcero.2016.52015 


\section{Introduction}

Cancer of the head and neck is the 6th most common cancer worldwide contributing 600,000 new cases of cancer every year and more than $95 \%$ of those cases are squamous cell carcinomas [1]. The majority of patients with head and neck cancer (H\&N cancer) are diagnosed as locally advanced diseases which are treated with combined surgery, radiotherapy and chemotherapy. Although recent advances in diagnosis and cancer therapy have improved 5-year survival rates by $10 \%$ in patients with $H \& N$ cancer, locoregional recurrence and distant metastasis are the main causes of treatment failure which occurs in $30 \%-40 \%$ of the patients.

In clinical practice, patients with $H \& N$ cancer who have the same TNM stage and undergo similar treatments have various clinical outcomes due to the heterogeneity of the tumor, suggesting that the TNM staging system might be inadequate for prognostic prediction for $\mathrm{H} \& \mathrm{~N}$ cancer. Therefore, development of new biomarkers as an adjunct to traditional staging system would facilitate establishing more appropriate patient-specific treatment strategies.

Recent researches have revealed that circulating tumor cells (CTCs) in peripheral blood may serve as a potential biomarker. CTCs, which were first reported by Ashworth in 1869 [2], are tumor cells circulating in blood vessels and sheltered subsets with metastasis-initiating ability [3]. CTCs have been detected in various cancers and the relationship between CTCs, and clinicopathological and prognostic significance have been reported in breast cancer [4] [5], gastric [6] and colorectal cancer [7]. However, there still remains controversial regarding clinical significance of CTCs in patients with H\&N cancer.

The aim of this study was to use a meta-analysis to comprehensively investigate the relationship between the presence of CTCs and clinicopathological significance of CTCs in H\&N cancers, and to explore its potential prognostication impact.

\section{Methods}

\subsection{Search Strategy}

PubMed, Embase, the Science Citation Index, Cochrane databases and the Ovid Database were systematically searched for studies investigating the tumor clinicopathological and prognostic relationship between CTCs and $\mathrm{H} \& \mathrm{~N}$ cancer, with no restrictions on language, place of publication or date of publication (up to November 2015). The main search terms used were "circulating tumor cells", "disseminated tumor cells", "head and neck cancer", "nasopharyngeal", "nasal", "oral", "oropharyngeal", "hypopharyngeal", "laryngeal", and "larynx".

\subsection{Eligibility Criteria}

To make our analysis reliable, we screened the titles and abstracts for all searched papers, and full text was perused for potential eligible studies according to the following inclusion criteria: 1) containing patient cases of $\mathrm{H} \& \mathrm{~N}$ cancer; 2) measuring the presence of CTCs in peripheral blood (PB); 3) investigating the clinicopathological and prognostic significance of CTCs in H\&N cancer patients with at least one of the outcome measures of interest. Studies were excluded in our study: 1) duplicated publications; 2) no outcomes of interest that were provided or can't be calculated for prognostic evaluation.

\subsection{Data Extraction}

Two reviewers (Chen RW and Zhou Y) independently evaluated each papers and extracted data, and any disagreements were resolved via discussion, with a third investigator if necessary. The following information was extracted: first author, publication year, population characteristics (i.e., country, number, sex and age), tumor clinicopathological characteristics (i.e. anatomical sites, pathologic differentiation and TNM stage), sampling times (preoperative or postoperative), detection methods (RT-PCR array, Non-RT-PCR array including Cell Search system or immunocytochemistry), CTCs positive rate, detection markers, endpoints and survival data. For studies with multiple markers or detect methods, each of the cohorts was considered an independent data set. However, for those studies with multiple sample times (i.e. pre-treatment and intra/post-treatment), we use data from pre-treatment samples because those data were usually dependent from various treatment regimens.

\subsection{Statistical Approaches}

Statistical analysis was performed using Review Manager 5.2 (Copenhagen: The Nordic Cochrane Centre; The 
Cochrane Collaboration, 2012). To evaluate the association between CTCs and clinicopathological characteristics, the estimated odd ratios (ORs) were extracted from enrolled publications. To statistically assess the prognostic significance (DFS and OS), we extracted the estimated hazard ratios (HRs) and associated 95\% CIs when available. If the HR and its variance were not reported directly in the original study, these values were calculated from available reported data using software designed by Tierney JF [8]. When HRs was presented by both univariate and multivariate analyses, the multivariate ones were employed due to adjustment for confounding factors. Heterogeneity among the studies was tested using the $\chi^{2}$ test and $I^{2}$ statistic. A value of $I^{2}<25 \%$, within $25 \%-50 \%$ or more than $50 \%$ was regarded as low, moderate, or significant heterogeneity, respectively. The random-effects mode was explored to perform the analyses, because this model obtained more conservative results than the fixed-effect model [9]. A two-sided $\mathrm{P}<0.05$ was considered statistically significant. Furthermore, subgroup analyses were made to explore the inherent heterogeneity. Lastly, the potential publication bias was evaluated using the funnel plot. All of the studies included in this research were assessed by referring to the Newcastle-Ottawa quality assessment scale (NOS) for cohort studies.

\section{Results}

\subsection{Baseline Characteristics}

The primary literature research initially yielded 2320 articles. After screening the titles, abstracts, language and other information, 2161 studies were excluded and 159 potential studies were reviewed further. An additional 137 studies were then excluded which were reviews $(n=18)$, laboratory studies $(n=97)$ or studies of other tumors $(n=22)$. Upon detailed evaluation of the remaining 22 studies, 5 studies had to be excluded because the outcome of interest could not be calculated. Finally, a total of 17 articles were considered to be appropriate for the meta-analysis (Figure 1).

The eligible 17 studies comprising 816 patients diagnosed as head and neck squamous cell carcinoma were published between 1999 and 2014 [10]-[26]. RT-PCR arrays were used to evaluate CTCs status in 6 studies, Cell Search system in 6 studies and immunocytochemistry (ICC) and other methods in the remaining studies. One study from the United Kingdom applied both RT-PCR and ICC and compared the agreement between these two methods, which was considered as two independent cohorts in the analysis. The samples for CTCs array were collected pre-treatment in 14 studies, only 2 studies [11] [21] were collected post-treatment and 1 study not reported. The main characteristics of the included studies are summarized in Table 1 . The quality of the in-

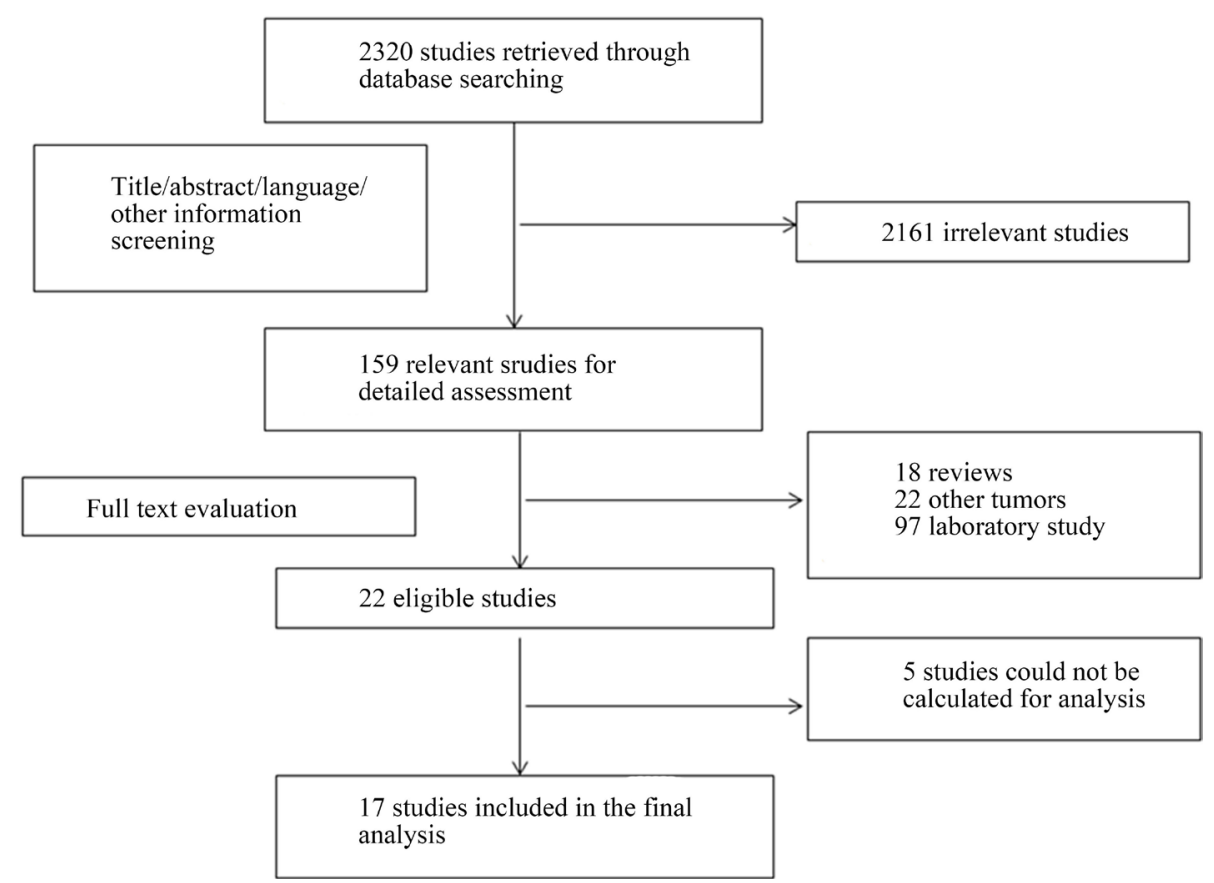

Figure 1. Selection of studies. Flow diagram showing the selection process for the enrolled studies. 


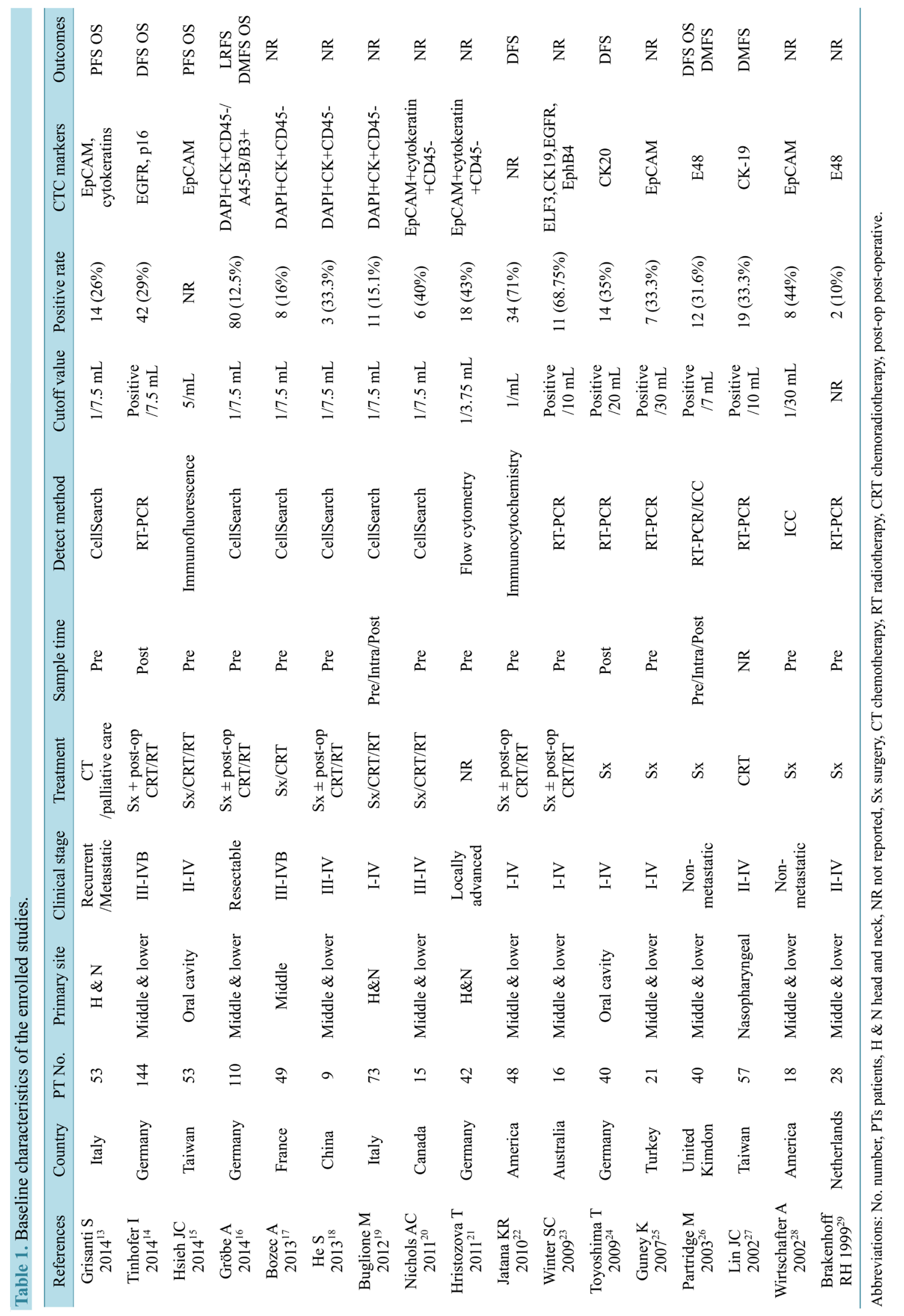


cluded studies was evaluated with the NOS and is summarized in Table 2.

\subsection{Correlation between CTCs and Clinicopathological Parameters}

\subsubsection{T Stage and CTCs}

A total of 10 studies reported the relationship between CTCs and T stage included in this meta-analysis. The $\chi^{2}$ test showed low to moderate heterogeneity among the studies (T1 vs. T2-4: $\mathrm{P}=0.27 ; I^{2}=19 \%$; T1-2 vs. T3-4: $\mathrm{P}$ $\left.=0.14 ; I^{2}=35 \%\right)$. The data suggested modest association in CTCs and T stage [T1 vs. T2-4: OR $1.24,95 \% \mathrm{CI}$ $(0.48,3.21), \mathrm{n}=10, \mathrm{P}=0.66$; T1-2 vs. T3-4: OR 0.70, 95\% CI $(0.31,1.58), \mathrm{n}=9, \mathrm{P}=0.39$ ] (Figure 2).

\subsubsection{N Stage and CTCs}

A total of 10 studies reported the difference of CTCs in $\mathrm{N}$ stage in this meta-analysis. Considering different combination of $\mathrm{N}$ stage, we divided into two situations: $\mathrm{N}$ negative vs. $\mathrm{N}$ positive and N0-1 vs. N2-3.

When considering N0-1 vs. N2-3, there were 10 studies included and the $\chi^{2}$ test showed no significant heterogeneity among the studies $\left(\mathrm{P}=0.50 ; I^{2}=0 \%\right)$. The result suggested that the presence of CTCs was significantly correlated with advanced $\mathrm{N}$ stage [OR $0.50,95 \% \mathrm{CI}(0.30,0.81), \mathrm{n}=10, \mathrm{P}=0.005]$.

When considering $\mathrm{N}$ negative vs. $\mathrm{N}$ positive, there were 12 studies included and the $\chi^{2}$ test showed moderate heterogeneity among the studies $\left(\mathrm{P}=0.18 ; I^{2}=27 \%\right)$. The result suggested a trend of association in CTCs and $\mathrm{N}$ stage without statistical significance [OR $0.59,95 \% \mathrm{CI}(0.30,1.18), \mathrm{n}=11, \mathrm{P}=0.13$ ] (Figure 3).

\subsubsection{Clinical Stage and CTCs}

A total of 10 studies reported the difference of CTCs in the clinical stage in this meta-analysis. The $\chi^{2}$ test showed moderate heterogeneity among the studies (I vs. II-IV: P $=0.35 ; I^{2}=10 \%$; I-II vs. III-IV: P $=0.11 ; I^{2}=$ $37 \%)$. The result suggested no statistically association in CTCs and clinical stage [I vs. II-IV: OR $2.03,95 \% \mathrm{CI}$ $(0.78,5.27), \mathrm{n}=10, \mathrm{P}=0.14$; I-II vs. III-IV: OR 0.68, 95\%CI $(0.30,1.54), \mathrm{n}=10, \mathrm{P}=0.35$ ] (Figure 4).

Table 2. Assessment of study quality using the Newcastle-Ottawa scale.

\begin{tabular}{|c|c|c|c|c|c|c|c|c|c|c|}
\hline \multirow{2}{*}{ References } & \multicolumn{4}{|c|}{ Selection $(0$ - 4) } & \multicolumn{2}{|c|}{ Comparability $(0$ - 2) } & \multicolumn{3}{|c|}{ Outcome (0 - 3) } & \multirow{2}{*}{ Tota } \\
\hline & REC & SNEC & $\mathbf{A E}$ & DO & SC & $\mathbf{A F}$ & AO & FU & AFU & \\
\hline Grisanti S $2014^{13}$ & 0 & 1 & 1 & 1 & 0 & 0 & 1 & 0 & 1 & 5 \\
\hline Tinhofer I $2014^{14}$ & 0 & 1 & 1 & 1 & 0 & 0 & 1 & 0 & 1 & 5 \\
\hline Hsieh JC $2014^{15}$ & 0 & 1 & 1 & 1 & 0 & 0 & 1 & 0 & 0 & 4 \\
\hline Gröbe A $2014^{16}$ & 0 & 1 & 1 & 1 & 0 & 0 & 1 & 0 & 1 & 5 \\
\hline Bozec $\mathrm{A}^{17}$ & 0 & 1 & 1 & 1 & 0 & 0 & 1 & 0 & 0 & 4 \\
\hline $\mathrm{He} \mathrm{S}^{18}$ & 0 & 1 & 1 & 1 & 0 & 0 & 1 & 0 & 1 & 5 \\
\hline Buglione $\mathrm{M}^{19}$ & 1 & 1 & 1 & 1 & 0 & 0 & 1 & 0 & 1 & 6 \\
\hline Nichols AC $2011^{20}$ & 0 & 1 & 1 & 1 & 0 & 0 & 1 & 0 & 1 & 5 \\
\hline Hristozova T $2011^{21}$ & 0 & 1 & 1 & 1 & 0 & 0 & 1 & 0 & 0 & 4 \\
\hline Jatana KR $2010^{22}$ & 1 & 1 & 1 & 1 & 0 & 0 & 1 & 0 & 1 & 6 \\
\hline Winter SC $2009^{23}$ & 1 & 1 & 1 & 1 & 0 & 0 & 1 & 0 & 1 & 6 \\
\hline Toyoshima T $2009^{24}$ & 1 & 1 & 1 & 1 & 0 & 0 & 1 & 1 & 1 & 7 \\
\hline Guney K $2007^{25}$ & 1 & 1 & 1 & 1 & 0 & 0 & 1 & 1 & 1 & 8 \\
\hline Partridge M $2003^{26}$ & 0 & 1 & 1 & 1 & 0 & 0 & 1 & 1 & 1 & 6 \\
\hline LIN JC $2002^{27}$ & 0 & 1 & 1 & 1 & 0 & 0 & 1 & 0 & 1 & 5 \\
\hline Wirtschafter A $2002^{28}$ & 1 & 1 & 1 & 1 & 0 & 0 & 1 & 0 & 0 & 5 \\
\hline Brakenhoff RH $1999^{29}$ & 1 & 1 & 1 & 1 & 0 & 0 & 1 & 0 & 1 & 6 \\
\hline
\end{tabular}

Abbreviations: REC: representativeness of the exposed cohort; SNEC: selection of the non-exposed cohort; AE: ascertainment of exposure; DO: demonstration that outcome of interest was not present at start of study; SC: study controls for age, sex; AF: study controls for any additional factors (chemoradiotherapy, curative resection); AO: assessment of outcome; FU: follow-up long enough for outcomes to occur; AFU: adequacy of follow-up of cohorts ( $\geq 90 \%)$. ' 1 ' means that the study is satisfied the item, and ' 0 ' means the opposite situation. 


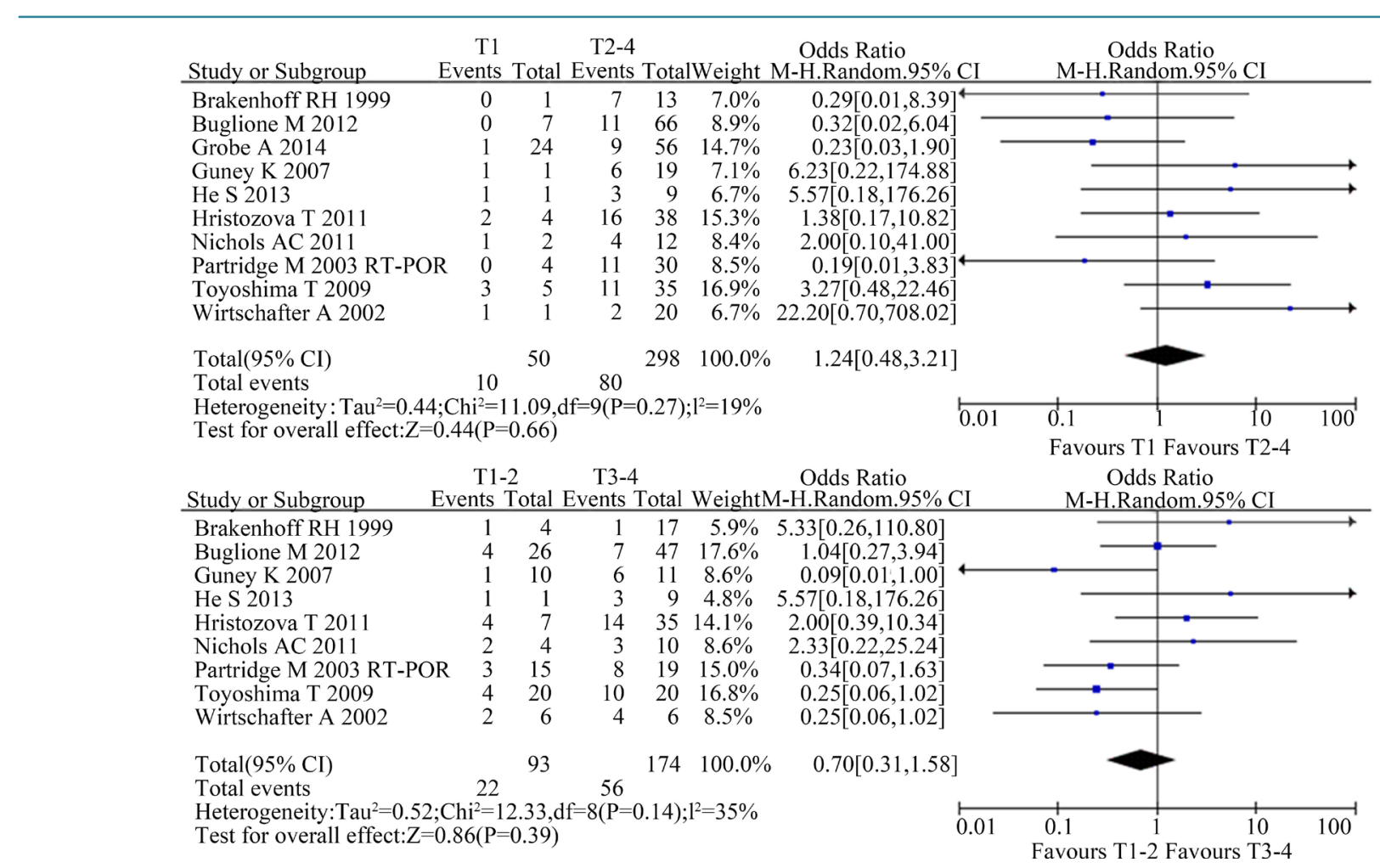

Figure 2. Estimated odds radios (OR) for T stage. (a) Forest plot of the relationship in T1 group relative to T2-4 group; (b) Forest plot of the relationship in T1-2 group relative to T3-4 group.

\begin{tabular}{|c|c|c|c|c|c|c|c|c|c|c|}
\hline Study or Subgroup & $\begin{array}{l}\mathrm{N} 0-1 \\
\text { Events }\end{array}$ & Total & $\begin{array}{l}\mathrm{N} 2-3 \\
\text { Events }\end{array}$ & Totall & Weight $\mathrm{N}$ & \multicolumn{2}{|c|}{$\begin{array}{l}\text { Odds Ratio } \\
\text { M-H.Random. } 95 \% \text { CI }\end{array}$} & \multicolumn{3}{|c|}{$\begin{array}{c}\text { Odds Ratio } \\
\text { M-H.Random. } 95 \% \text { CI }\end{array}$} \\
\hline Brakenhoff RH 1999 & 1 & 13 & 1 & 8 & $2.8 \%$ & $0.58[0.03,10.86]$ & & & & \\
\hline Buglione M 2012 & 4 & 26 & 7 & 47 & $13.6 \%$ & $1.04[0.27,3.94]$ & & & & \\
\hline Grobe A 2014 & 8 & 58 & 2 & 22 & $9.1 \%$ & $1.60[0.31,8.20]$ & & & & \\
\hline Guney K 2007 & 7 & 21 & 1 & 1 & $2.2 \%$ & $0.17[0.01,4.77]$ & & & & \\
\hline He S 2013 & 0 & 4 & 3 & 5 & $2.2 \%$ & $0.08[0.00,2.24]$ & & & & \\
\hline Hristozova T 2011 & 4 & 16 & 14 & 26 & $12.9 \%$ & $0.29[0.07,1.12]$ & & & & \\
\hline Nichols AC 2011 & 3 & 8 & 3 & 7 & $5.7 \%$ & $0.80[0.10,6.35]$ & & & & \\
\hline Partridge M 2003 RT-POR & R 5 & 22 & 6 & 12 & $10.7 \%$ & $0.29[0.07,1.33]$ & & & & \\
\hline Tinhofer I 2014 & 11 & 53 & 30 & 89 & $38.3 \%$ & $0.52[0.23,1.14]$ & & & & \\
\hline Wirtschafter A 2002 & 5 & 22 & 3 & 3 & $2.5 \%$ & $0.04[0.00,1.01]$ & & & & \\
\hline Total $(95 \%$ CI $)$ & & 243 & & 220 & $100.0 \%$ & $0.50[0.30,0.81]$ & & & & \\
\hline Total events & 48 & & 70 & & & & & & & \\
\hline $\begin{array}{l}\text { Heterogeneity: } \mathrm{Tau}^{2}=0.00 ; \\
\text { Test for overall effect: } \mathrm{Z}=2 \text {. }\end{array}$ & $\begin{array}{l}; \mathrm{Chi}^{2}= \\
2.78(\mathrm{P}=\end{array}$ & $\begin{array}{l}8.31, \mathrm{c} \\
=0.00\end{array}$ & $\begin{array}{l}d f=9(P= \\
15)\end{array}$ & $=0.50)$ & $; 1^{2}=0 \%$ & & 0.01 & $\begin{array}{l}0.1 \\
\text { Favours N0- }\end{array}$ & 1 Favours N2-3 & 100 \\
\hline Study or Subgroup & $\begin{array}{c}\mathrm{N}- \\
\text { EventsT }\end{array}$ & Total I & $\begin{array}{r}\mathrm{N}+ \\
\text { Events }\end{array}$ & Totall & Weight $\mathrm{N}$ & $\begin{array}{c}\text { Odds Ratio } \\
\text { M-H.Random. } 95 \% \\
\end{array}$ & & $\begin{array}{r}\text { Odds } \\
\text { M-H.Ranc }\end{array}$ & $\begin{array}{l}\text { Ratio } \\
\text { dom. } 95 \% \mathrm{CI}\end{array}$ & \\
\hline Bozec A 2013 & 1 & 19 & 7 & 30 & $7.7 \%$ & $0.18[0.02,1.62]$ & & & F & \\
\hline Brakenhoff RH 1999 & 1 & 12 & 1 & 9 & $4.8 \%$ & $0.73[0.04,13.45]$ & & & & \\
\hline Buglione M 2012 & 4 & 18 & 7 & 55 & $14.5 \%$ & $1.96[0.50,7.67]$ & & & & \\
\hline Grobe A 2014 & 5 & 38 & 5 & 70 & $15.2 \%$ & $1.97[0.53,7.29]$ & & & & \\
\hline Guney K 2007 & 3 & 14 & 4 & 7 & $9.0 \%$ & $0.20[0.03,1.46]$ & & & - & \\
\hline He S 2013 & 0 & 1 & 3 & 8 & $3.5 \%$ & $0.52[0.02,16.83]$ & & & & \\
\hline Hristozova T 2011 & 3 & 11 & 15 & 31 & $12.9 \%$ & $0.40[0.09,1.80]$ & & & & \\
\hline Nichols AC 2011 & 1 & 4 & 5 & 11 & $6.0 \%$ & $0.40[0.03,5.15]$ & & & & \\
\hline Partridge M 2003 RT-POR & 0 & 9 & 11 & 25 & $4.7 \%$ & $0.07[0.00,1.26]$ & & & & \\
\hline Tinhofer I 2014 & 0 & 14 & 41 & 128 & $5.0 \%$ & $0.07[0.00,1.25]^{4}$ & & & & \\
\hline Toyoshima T 2009 & 10 & 30 & 4 & 10 & $13.2 \%$ & $0.75[0.17,3.28]$ & & & & \\
\hline Wirtschafter A 2002 & 5 & 5 & 3 & 4 & $3.5 \%$ & $4.71[0.15,151.48]$ & & & & \\
\hline $\begin{array}{l}\text { Total }(95 \% \mathrm{CI}) \\
\text { Total events }\end{array}$ & 33 & 175 & 10 & $6^{388}$ & $100.0 \%$ & $0.59[0.30,1.18$ & & & & \\
\hline $\begin{array}{l}\text { Heterogeneity: } \mathrm{Tau}^{2}=0.37 ; \mathrm{C} \\
\text { Test for overall effect: } \mathrm{Z}=1 .\end{array}$ & $\begin{array}{l}\mathrm{Chi}^{2}=1 \\
1.50(\mathrm{P}=\end{array}$ & $\begin{array}{l}14.99, \\
=0.13\end{array}$ & $\mathrm{df}=11($ & $\mathrm{P}=0.1$ & $8) ; 1^{2}=27^{0}$ & & .01 & $\begin{array}{l}0.1 \\
\text { Favours N- }\end{array}$ & $\begin{array}{c}10 \\
\text { Favours N+ }\end{array}$ & 100 \\
\hline
\end{tabular}

Figure 3. Estimated odds radios (OR) for N stage. (a) Forest plot of the relationship in N0-1 group relative to N2-3 group; (b) Forest plot of the relationship in $\mathrm{N}$ negative group relative to $\mathrm{N}$ positive group. 


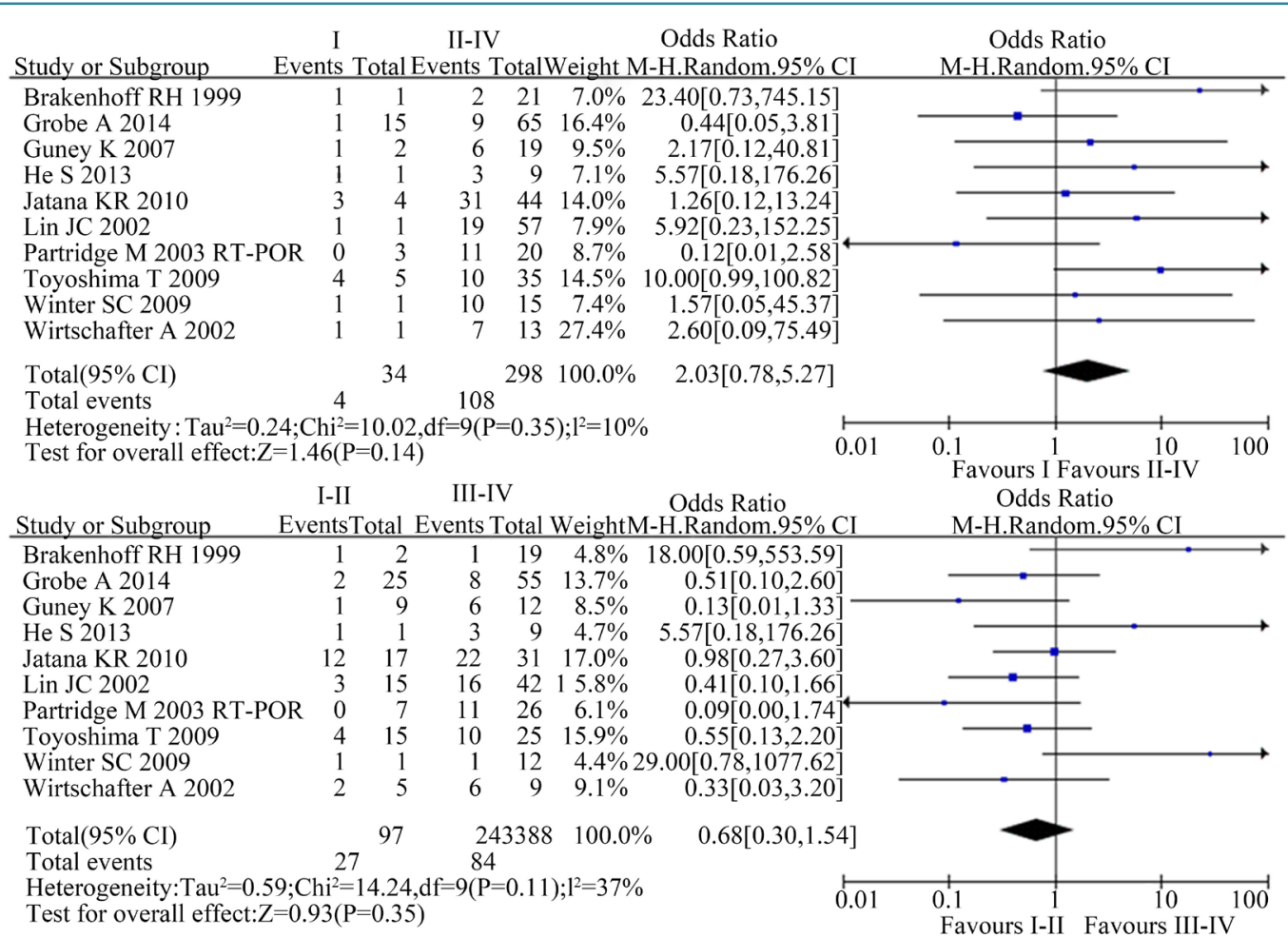

Figure 4. Estimated odds radios (OR) for total stage. (a) Forest plot of the relationship in I-II stage group relative to III-IV stage group; (b) Forest plot of the relationship in I stage group relative to II-IV stage group.

\subsubsection{Other Clinical Parameters and CTCs}

The difference between CTCs and age, sex, alcohol abuse, smoking history, anatomical sites and tumor grades was not statistically significant (data not shown).

\subsection{Correlation between CTCs and Treatment Outcomes}

\subsubsection{DFS and CTCs}

There were 5 studies presenting relationship between CTCs and DFS with only 1 study which gave the HR and $95 \%$ CI for DFS directly [11], and other 4 studies with HR and 95\%CI of DFS which were calculated using the survival curves and the $P$ values [19] [21] [23] The $\chi^{2}$ test showed low heterogeneity among the above studies (P $\left.=0.43 ; I^{2}=0 \%\right)$. The combined pooled HR of the above studies by a random-effects model was $1.73(95 \% \mathrm{CI}$ $1.01-2.96, \mathrm{P}=0.050$ ), indicating that high CTCs level was significantly associated with a poor DFS in patients with H\&N cancer (Figure 5(a)).

\subsubsection{OS and CTCs}

Similarly, HR and 95\%CI for OS was directly extracted from the above 2 articles [10] [11], and HRs and 95\%CI for the remaining 1 study [23] was calculated using the survival curves and the $P$ values. The $\chi^{2}$ test showed moderate heterogeneity among the above studies ( $\left.\mathrm{P}=0.16 ; I^{2}=43 \%\right)$. The pooled HR with a random-effects model was $2.53(95 \% \mathrm{CI} 1.37-4.69, \mathrm{P}=0.003)$, suggesting a significant lower OS in $\mathrm{H} \& \mathrm{~N}$ cancer patients with CTCs positivity (Figure $5(\mathrm{~b})$ ).

\subsection{Subgroup Analysis}

\subsubsection{Detect Methods: RT-PCR and Non-RT-PCR}

In RT-PCR group, the OR and $95 \% \mathrm{CI}$ for T stage and $\mathrm{N}$ stage was $0.34(95 \% \mathrm{CI} 0.10-0.1 .10, \mathrm{P}=0.07)$ and $0.44(95 \%$ CI $0.23-0.87, \mathrm{P}=0.02)$. The HR and $95 \% \mathrm{CI}$ for DFS and OS was $1.55(95 \% \mathrm{CI} 0.77-3.13, \mathrm{P}=0.22)$ and $1.58(95 \% \mathrm{CI} 0.83-3.02, \mathrm{P}=0.17)$, respectively. Whereas, in the non-RT-PCR group, there is no significant relationship between $\mathrm{T}$ stage and $\mathrm{N}$ stage with CTCs detection. The HR and 95\%CI for DFS (3.70, 95\%CI 0.96 - 


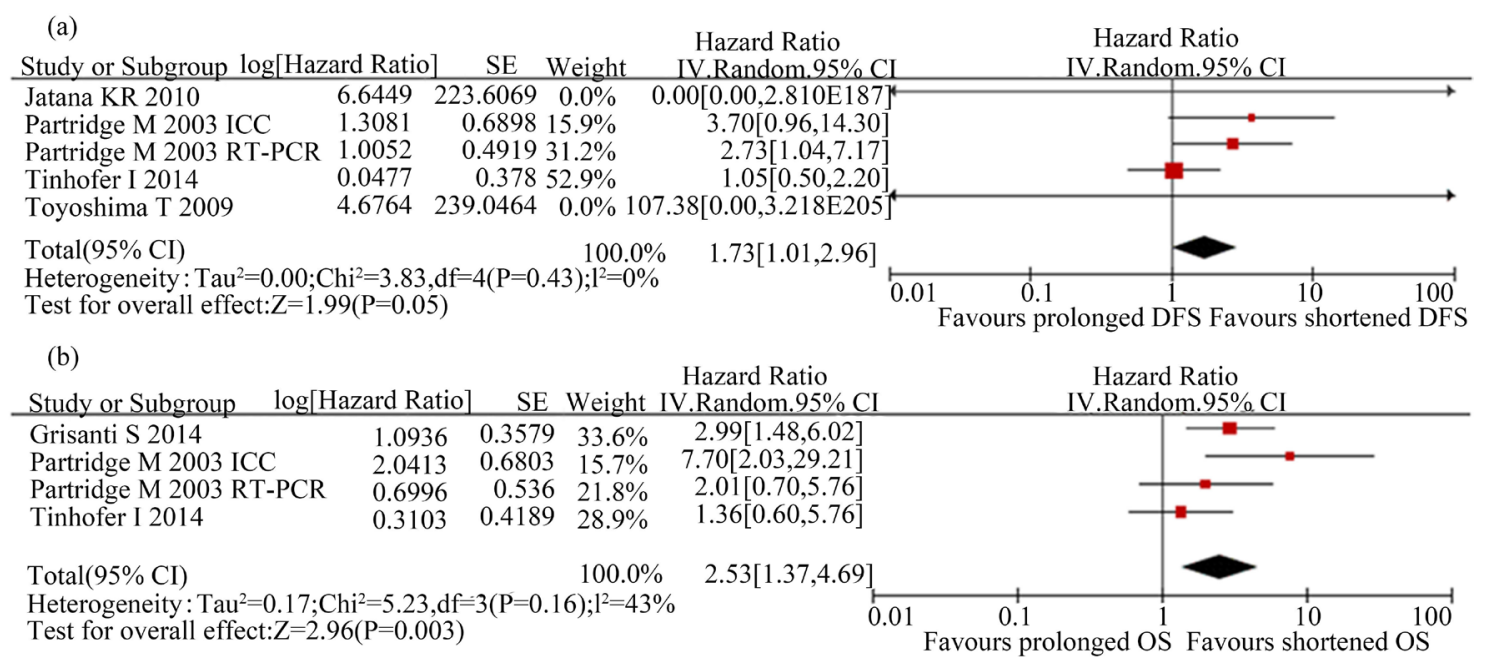

Figure 5. Estimated hazard ratios (HR) for DFS and OS. (a) Forest plot of disease-free survival (DFS) in all patients; (b) Forest plot of overall survival (OS) in all patients.

$14.30, \mathrm{P}=0.06)$ and $\mathrm{OS}(4.02,95 \% \mathrm{CI} 1.70-9.51, \mathrm{P}=0.002)$ were relatively higher than the RT-PCR group.

\subsubsection{Sampling Time: Pre- and Post-Treatment}

The relationship between T/N stage and the time of CTCs detection remains no statistical significance in both subgroups. In pre-treatment group, the HR and $95 \% \mathrm{CI}$ for DFS and OS were $3.03(95 \% \mathrm{CI} 1.38-6.63, \mathrm{P}=$ $0.0006)$ and $3.19(95 \% \mathrm{CI} 1.73-5.90, \mathrm{P}=0.0002)$ respectively. However, if the sampling time was post treatment, the HR and 95\% CI for DFS and OS were $1.05(95 \% \mathrm{CI} 0.50-2.20, \mathrm{P}=0.09)$ and $1.36(95 \% \mathrm{CI} 0.60-3.10$, $\mathrm{P}=0.46$ ), respectively. The more detailed data are shown in Table 3 .

\subsubsection{Sensitivity Analysis and Publication Bias}

There was no obvious publication bias seen in this meta-analysis (Figure 6(a), Figure 6(b)).

\section{Discussion}

Comprehensive multidisciplinary strategies have widely been applied in the primary treatment of locally advanced $H \& N$ cancer. Whereas the occurrence of local recurrence and distant metastasis still remains the leading cause of cancer-related deaths. There is an urgent demand to explore simple and reliable prognostic biomarkers for individualized cancer treatment. Among various biomarkers, detection of CTCs in PB may be a promising method and its correlation with clinicopathological features and prognostic significance has been investigated in breast cancer, gastrointestinal cancer and prostate cancer for many years. The clinical significance of CTCs in $\mathrm{H} \& \mathrm{~N}$ cancer has not been thoroughly investigated. Therefore, we performed this pooled study and demonstrated presence of CTCs was significantly associated with higher N stage and poorer prognosis in patients with H\&N cancer.

It is well known that survival of patients with $\mathrm{H} \& \mathrm{~N}$ cancer is associated with several clinicalpathological factors, including tumor grade and TNM stage and so on. Liao et al. reported in a meta-analysis that presence of CTCs was significantly associated with tumor size, tumor grade, ER and PR status in patients with breast cancer [4]. Similar findings were reported in gastric cancer, showing a correlation of positive CTCs detection with high tumor stage, lymph node involvement, Lauren diffuse group and poorly differentiation [27]. In our pooled study, we found that significantly higher detection rate of CTCs in lymph node positive group, which again confirmed the emerging evidence that presence of CTCs in PB is associated with more aggressive clinicopathological feature of malignancies.

The prognostic significance of CTCs in H\&N cancer has been controversial in a series of studies. In our enrolled studies, Grisantis S et al. prospectively reported that pre-treatment detection of CTCs was associated with poorer PFS and OS [10]. Controversially, Tinhofer I et al. showed that there was no correlation between post-operative CTCs positivity and overall survival [11]. This discrepancy between studies may be due to hete- 
Table 3. Results of subgroup analyses on TNM stage, DFS and OS.

\begin{tabular}{|c|c|c|c|c|c|c|}
\hline \multirow{2}{*}{\multicolumn{2}{|c|}{ Variables }} & \multirow{2}{*}{ Overall } & \multicolumn{2}{|c|}{ Detect method } & \multicolumn{2}{|c|}{ Sampling time } \\
\hline & & & RT-PCR & Non-RT-PCR & Pre-treatment & Post-treatment \\
\hline \multirow{5}{*}{$\begin{array}{c}\text { T stage } \\
(\mathrm{T} 1-2: \mathrm{T} 3-4)\end{array}$} & $\mathrm{n}$ & 9 & 4 & 5 & 8 & 1 \\
\hline & OR & 0.70 & 0.34 & 1.27 & 0.86 & 0.25 \\
\hline & $95 \% \mathrm{CI}$ & $0.31-1.58$ & $0.10-1.10$ & $0.54-3.00$ & $0.36-2.06$ & $0.06-1.02$ \\
\hline & $I^{2}$ & $35 \%$ & $33 \%$ & $0 \%$ & $30 \%$ & I \\
\hline & $P$ & 0.39 & 0.07 & 0.58 & 0.73 & 0.05 \\
\hline \multirow{5}{*}{$\begin{array}{c}\text { N stage } \\
\text { (N0-1: N2-3) }\end{array}$} & $\mathrm{n}$ & 10 & 4 & 6 & 9 & 1 \\
\hline & OR & 0.50 & 0.44 & 0.52 & 0.48 & 0.52 \\
\hline & $95 \% \mathrm{CI}$ & $0.30-0.81$ & $0.23-0.87$ & $0.21-1.32$ & $0.25-0.92$ & $0.23-1.14$ \\
\hline & $I^{2}$ & $0 \%$ & $0 \%$ & $32 \%$ & $4 \%$ & l \\
\hline & $P$ & 0.005 & 0.02 & 0.17 & 0.03 & 0.10 \\
\hline \multirow{5}{*}{$\begin{array}{c}\text { Clinical stage } \\
\text { (I-II: III-IV) }\end{array}$} & $\mathrm{n}$ & 10 & 6 & 4 & 9 & 1 \\
\hline & OR & 0.68 & 0.69 & 0.76 & 0.73 & 0.55 \\
\hline & $95 \% \mathrm{CI}$ & $0.30-1.54$ & $0.17-2.85$ & $0.31-1.87$ & $0.27-1.94$ & $0.13-2.20$ \\
\hline & $I^{2}$ & $37 \%$ & $57 \%$ & $0 \%$ & $44 \%$ & I \\
\hline & $P$ & 0.35 & 0.61 & 0.56 & 0.53 & 0.39 \\
\hline \multirow{5}{*}{ DFS } & $\mathrm{n}$ & 5 & 3 & 2 & 3 & 2 \\
\hline & HR & 1.73 & 1.55 & 3.70 & 3.03 & 1.05 \\
\hline & $95 \% \mathrm{CI}$ & $1.01-2.96$ & $0.77-3.13$ & $0.96-14.30$ & $1.38-6.63$ & $0.50-2.20$ \\
\hline & $I^{2}$ & $0 \%$ & $16 \%$ & $0 \%$ & $0 \%$ & $0 \%$ \\
\hline & $P$ & 0.05 & 0.22 & 0.06 & 0.006 & 0.90 \\
\hline \multirow{5}{*}{ OS } & $\mathrm{n}$ & 4 & 2 & 2 & 3 & 1 \\
\hline & HR & 2.53 & 1.58 & 4.02 & 3.19 & 1.36 \\
\hline & $95 \% \mathrm{CI}$ & $1.37-4.69$ & $0.83-3.02$ & $1.70-9.51$ & $1.73-5.90$ & $0.60-3.10$ \\
\hline & $I^{2}$ & $43 \%$ & $0 \%$ & $34 \%$ & $18 \%$ & I \\
\hline & $P$ & 0.003 & 0.17 & 0.002 & 0.0002 & 0.46 \\
\hline
\end{tabular}

(a)

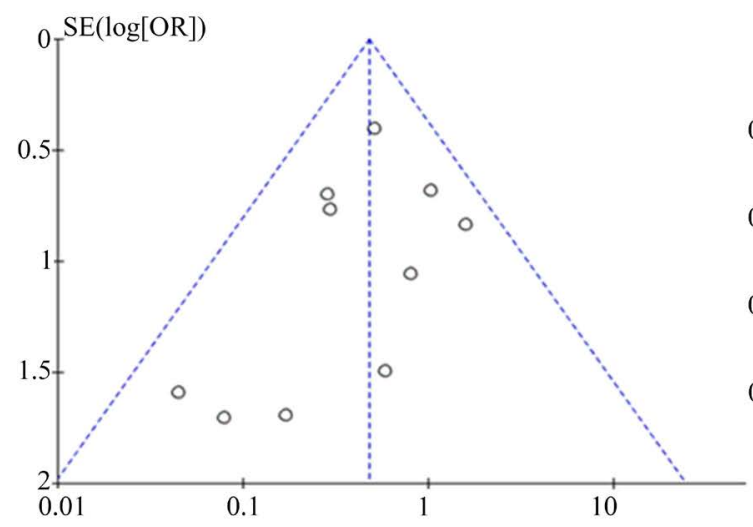

(b)

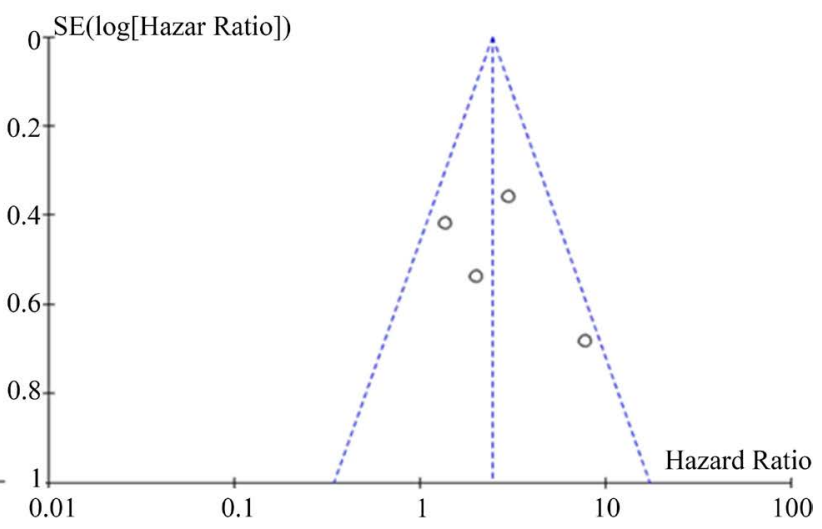

Figure 6. Funnel plots of the enrolled studies. (a) N stage; (b) Overall survival (OS).

rogeneity of study design, tumor stage, sampling time and detect methods of the enrolled studies, suggesting the necessity of a meta-analysis on this issue. In the present pooled study, we revealed that CTCs showed significant prognostication in terms of DFS and OS in patients with H\&N cancer. Further analyses demonstrated that DFS 
and OS maintained statistically significant with detection array with Non-RT-PCR and pre-treatment sampling of CTCs.

Various approaches have been reported to detect CTCs in PB including RT-PCR, Cell Search System and ICC staining. For convenience we classified these arrays into RT-PCR and Non-RT-PCR. Our research suggested that positive CTCs detected by RT-PCR array may be associated with advanced T stage and N stage whereas Non-RT-PCR methods, mainly Cell Search system seemed to be superior to RT-PCR array in predicting DFS and OS. The Cell Search System is the unique method of CTC identification approved in metastatic breast cancer, prostate cancer and colorectal cancer, by the Food and Drug Administration in the United States. The inferiority of RT-PCR methods may be due to the relatively high rate of false positive cases from non-neoplastic and contaminated samples [28] [29]. Of note, there are still problems in the sensitivity, reproducibility and reliability of various detect approaches and much effort should be put in applying of standardized methods to decrease the intra-study inconsistencies.

Interestingly, we also observed heterogeneity from different detect time in predicting OS and DFS, with more prominent HRs from pre-treatment subgroup. This is reasonable that CTCs detection before any interventions actually indicates baseline information of CTCs burden and should be more pathologically meaningful to estimate the patient survival. Meanwhile, CTCs detection as a prognostic biomarker may develop a maximal value in a pre-treatment setting for more individualized therapy. Other researchers believed that post-treatment CTCs may incorporate the pretreatment status of CTCs and also estimate the number of tumor cells released during surgical operation for patients with pancreatic cancer patients [30]. The actual underlying meaning for different effects of CTCs before and after treatment remains ambiguous which deserves to be investigated in future studies.

Certain limitations still existed in the present study. Firstly, the individual information of enrolled studies was not available. Secondly, although the clinical significance was further discussed in subgroup analysis, the intraand inter-study heterogeneity with regard to patient characteristics, detect methods and sampling time still remains inevitable. Thirdly, the optimal CTCs cutoff value for predicting the outcomes in H\&N cancer is still under investigation and there is no uniform cutoff value to define high level of CTCs. Despite these limitations, our meta-analysis demonstrated the clinicopathological and prognostic significance of circulating tumor cells (CTCs) in periphery blood for patients with $\mathrm{H} \& \mathrm{~N}$ cancer.

\section{Conclusion}

Our meta-analysis has indicated that the presence of CTCs in peripheral blood is associated with higher N stage and poorer prognosis in patients with H\&N cancer. Detection of pre-treatment CTCs using Non-RT-PCR arrays might serve as a prognostic biomarker to guide individualized treatment. High-qualified, well-designed and large-scaled multicenter studies are urgently demanded to explore its potential as a biomarker for clinicopathological and prognostic significance in patients with $H \& N$ cancer.

\section{Funding}

This work was funded by National Natural Science Foundation of China (No. 81172209); Guangdong Natural Science Foundation (No. S2011020003612).

\section{Conflict of Interest}

The authors declare that they have no conflict of interest.

\section{Ethical Approve}

For this type of study form consent is not required.

\section{References}

[1] Belcher, R., Hayes, K., Fedewa, S. and Chen, A.Y. (2014) Current Treatment of Head and Neck Squamous Cell Cancer. Journal of Surgical Oncology, 110, 551-574. http://dx.doi.org/10.1002/jso.23724

[2] Ashworth, T.R. (1869) A Case of Cancer in Which Cells Similar to Those in the Tumors Were Seen in the Blood after 
Death. Medical Journal of Australia, 14, 146-149.

[3] Valastyan, S. and Weinberg, R.A. (2011) Tumor Metastasis: Molecular Insights and Evolving Paradigms. Cell, 147, 275-292. http://dx.doi.org/10.1016/i.cell.2011.09.024

[4] Liao, Y., Wang, S.Y., Meng, X.Y., Yang, J., Shi, M.J., Liu, H.L., et al. (2014) Circulating Tumor Cells in Breast Cancer and Its Association with Tumor Clinicopathological Characteristics: A Meta-Analysis. Medical Oncology, 31, 343. http://dx.doi.org/10.1007/s12032-014-0343-7

[5] Cristofanilli, M., Budd, G.T., Ellis, M.J., Stopeck, A., Matera, J., Miller, M.C., et al. (2004) Circulating Tumor Cells, Disease Progression, and Survival in Metastatic Breast Cancer. The New England Journal of Medicine, 351, $781-791$. http://dx.doi.org/10.1056/NEJMoa040766

[6] Yie, S.M., Lou, B., Ye, S.R., Cao, M., He, X., Li, P., et al. (2008) Detection of Survivin-Expressing Circulating Cancer Cells (CCCs) in Peripheral Blood of Patients with Gastric and Colorectal Cancer Reveals High Risks of Relapse. Annals of Surgical Oncology, 15, 3073-3082. http://dx.doi.org/10.1245/s10434-008-0069-x

[7] Cohen, S.J., Punt, C.J., Iannotti, N., Saidman, B.H., Sabbath, K.D., Gabrail, N.Y., et al. (2008) Relationship of Circulating Tumor Cells to Tumor Response, Progression-Free Survival, and Overall Survival in Patients with Metastatic Colorectal Cancer. Journal of Clinical Oncology, 26, 3213-3221. http://dx.doi.org/10.1200/JCO.2007.15.8923

[8] Tierney, J.F., Stewart, L.A., Ghersi, D., Burdett, S. and Sydes, M.R. (2007) Practical Methods for Incorporating Summary Time-to-Event Data into Meta-anaLysis. Trials, 8, 16. http://dx.doi.org/10.1186/1745-6215-8-16

[9] Schmidt, F.L., Oh, I.S. and Hayes, T.L. (2009) Fixed-Versus Random-Effects Models in Meta-Analysis: Model Properties and an Empirical Comparison of Differences in Results. British Journal of Mathematical and Statistical Psychology, 62, 97-128. http://dx.doi.org/10.1348/000711007X255327

[10] Grisanti, S., Almici, C., Consoli, F., Buglione, M., Verardi, R., Bolzoni-Villaret, A., et al. (2014) Circulating Tumor Cells in Patients with Recurrent or Metastatic Head and Neck Carcinoma: Prognostic and Predictive Significance. PLoS One, 9, e103918. http://dx.doi.org/10.1371/journal.pone.0103918

[11] Tinhofer, I, Konschak, R., Stromberger, C., Raguse, J.D., Dreyer, J.H., Johrens, K., et al. (2014) Detection of Circulating Tumor Cells for Prediction of Recurrence after Adjuvant Chemoradiation in Locally Advanced Squamous Cell Carcinoma of the Head and Neck. Annals of Oncology, 25, 2042-2047. http://dx.doi.org/10.1093/annonc/mdu271

[12] Hsieh, J.C., Lin, H.C., Huang, C.Y., Hsu, H.L., Wu, T.M., Lee, C.L., et al. (2014) Prognostic Value of Circulating Tumor Cells with Podoplanin Expression in Patients with Locally Advanced or Metastatic Head and Neck Squamous Cell Carcinoma. Head Neck, 37, 1448-1455.

[13] Grobe, A., Blessmann, M., Hanken, H., Friedrich, R.E., Schon, G., Wikner, J., et al. (2014) Prognostic Relevance of Circulating Tumor Cells in Blood and Disseminated Tumor Cells in Bone Marrow of Patients with Squamous Cell Carcinoma of the Oral Cavity. Clinical Cancer Research, 20, 425-433. http://dx.doi.org/10.1158/1078-0432.CCR-13-1101

[14] Bozec, A., Ilie, M., Dassonville, O., Long, E., Poissonnet, G., Santini, J., et al. (2013) Significance of Circulating Tumor Cell Detection Using the Cell Search System in Patients with Locally Advanced Head and Neck Squamous Cell Carcinoma. European Archives of Oto-Rhino-Laryngology, 270, 2745-2749. http://dx.doi.org/10.1007/s00405-013-2399-y

[15] He, S., Li, P., Long, T., Zhang, N., Fang, J. and Yu, Z. (2013) Detection of Circulating Tumour Cells with the Cell Search System in Patients with Advanced-Stage Head and Neck Cancer: Preliminary Results. Journal of Laryngology and Otology, 127, 788-793. http://dx.doi.org/10.1017/S0022215113001412

[16] Buglione, M., Grisanti, S., Almici, C., Mangoni, M., Polli, C., Consoli, F., et al. (2012) Circulating Tumour Cells in Locally Advanced Head and Neck Cancer: Preliminary Report about Their Possible Role in Predicting Response to Non-Surgical Treatment and Survival. European Journal of Cancer, 48, 3019-3026. http://dx.doi.org/10.1016/j.ejca.2012.05.007

[17] Nichols, A.C., Lowes, L.E., Szeto, C.C., Basmaji, J., Dhaliwal, S., Chapeskie, C., et al. (2012) Detection of Circulating Tumor Cells in Advanced Head and Neck Cancer Using the CellSearch System. Head \& Neck, 34, 1440-1444. http://dx.doi.org/10.1002/hed.21941

[18] Hristozova, T., Konschak, R., Stromberger, C., Fusi, A., Liu, Z., Weichert, W., et al. (2011) The Presence of Circulating Tumor Cells (CTCs) Correlates with Lymph Node Metastasis in Nonresectable Squamous Cell Carcinoma of the Head and Neck Region (SCCHN). Annals of Oncology, 22, 1878-1885. http://dx.doi.org/10.1093/annonc/mdr130

[19] Jatana, K.R., Balasubramanian, P., Lang, J.C., Yang, L., Jatana, C.A., White, E., et al. (2010) Significance of Circulating Tumor Cells in Patients with Squamous Cell Carcinoma of the Head and Neck: Initial Results. JAMA Otolaryngology—Head \& Neck Surgery, 136, 1274-1279. http://dx.doi.org/10.1001/archoto.2010.223

[20] Winter, S.C., Stephenson, S.A., Subramaniam, S.K., Paleri, V., Ha, K., Marnane, C., et al. (2009) Long Term Survival Following the Detection of Circulating Tumour Cells in Head and Neck Squamous Cell Carcinoma. BMC Cancer, 9 , 
424. http://dx.doi.org/10.1186/1471-2407-9-424

[21] Toyoshima, T., Vairaktaris, E., Nkenke, E., Schlegel, K.A., Neukam, F.W. and Ries, J. (2009) Hematogenous Cytokeratin 20 mRNA Detection Has Prognostic Impact in Oral Squamous Cell Carcinoma: Preliminary Results. Anticancer Research, 29, 291-297.

[22] Guney, K., Yoldas, B., Ozbilim, G., Derin, A.T., Sarihan, S. and Balkan, E. (2007) Detection of Micrometastatic Tumor Cells in Head and Neck Squamous Cell Carcinoma. A Possible Predictor of Recurrences? Saudi Medical Journal, 28, 216-220.

[23] Partridge, M., Brakenhoff, R., Phillips, E., Ali, K., Francis, R., Hooper, R., et al. (2003) Detection of Rare Disseminated Tumor Cells Identifies Head and Neck Cancer Patients at Risk of Treatment Failure. Clinical Cancer Research, 9 , 5287-5294.

[24] Lin, J.C., Chen, K.Y., Wang, W.Y., Jan, J.S., Liang, W.M. and Wei, Y.H. (2002) Evaluation of Cytokeratin-19 mRNA as a Tumor Marker in the Peripheral Blood of Nasopharyngeal Carcinoma Patients Receiving Concurrent Chemoradiotherapy. International Journal of Cancer, 97, 548-553. http://dx.doi.org/10.1002/ijc.10075

[25] Wirtschafter, A., Benninger, M.S., Moss, T.J., Umiel, T., Blazoff, K. and Worsham, M.J. (2002) Micrometastatic Tumor Detection in Patients with Head and Neck Cancer: A Preliminary Report. JAMA Otolaryngology-Head \& Neck Surgery, 128, 40-43. http://dx.doi.org/10.1001/archotol.128.1.40

[26] Brakenhoff, R.H., Stroomer, J.G., ten Brink, C., de Bree, R., Weima, S.M., Snow, G.B., et al. (1999) Sensitive Detection of Squamous Cells in Bone Marrow and Blood of Head and Neck Cancer Patients by E48 Reverse Transcriptase-Polymerase Chain Reaction. Clinical Cancer Research, 5, 725-732.

[27] Huang, X., Gao, P., Sun, J., Chen, X., Song, Y., Zhao, J., et al. (2015) Clinicopathological and Prognostic Significance of Circulating Tumor Cells in Patients with Gastric Cancer: A Meta-Analysis. International Journal of Cancer, 136, 21-33. http://dx.doi.org/10.1002/ijc.28954

[28] Mockelmann, N., Laban, S., Pantel, K. and Knecht, R. (2014) Circulating Tumor Cells in Head and Neck Cancer: Clinical Impact in Diagnosis and Follow-Up. European Archives of Oto-Rhino-Laryngology, 271, 15-21. http://dx.doi.org/10.1007/s00405-013-2391-6

[29] Jatana, K.R., Lang, J.C. and Chalmers, J.J. (2011) Identification of Circulating Tumor Cells: A Prognostic Marker in Squamous Cell Carcinoma of the Head and Neck? Future Oncology, 7, 481-484. http://dx.doi.org/10.2217/fon.11.19

[30] Ma, X.L., Li, Y.Y., Zhang, J., Huang, J.W., Jia, H.Y., Liu, L., et al. (2014) Prognostic Role of Circulating Tumor Cells in Patients with Pancreatic Cancer: A Meta-Analysis. Asian Pacific Journal of Cancer Prevention, 15, 6015-6020. http://dx.doi.org/10.7314/APJCP.2014.15.15.6015

\section{Abbreviations}

CTCs Circulating tumor cells; DFS Disease-free survival; OS Overall survival; DMFS distant metastasis-free survival; H\&N Cancer Head and neck carcinoma; $P B$ Peripheral blood; HR Hazard ratio; OR Odd ratio; ICC Immunocytochemistry; NOS Newcastle-Ottawa quality assessment scale. 